\title{
Photocatalytic Reduction of Se Ions Using Suspended Anatase Powders *1
}

\author{
Sumiko Sanuki ${ }^{1}$, Kazue Shako ${ }^{1, * 2}$, Shigeru Nagaoka ${ }^{2}$ and Hiroshi Majima ${ }^{3}$ \\ ${ }^{1}$ Department of Material Systems Engineering and Life Science, Faculty of Engineering, Toyama University, \\ Toyama 930-8555 \\ ${ }^{2}$ Research and Development Department, Titan Kogyo K.K., Ube 755-8567 \\ ${ }^{3}$ Professor Emeritus, Kyoto University, and Special Advisor, Titan Kogyo K.K., Ube 755-8567
}

The photocatalytic reduction of aqueous $\mathrm{Se}(\mathrm{VI})$ solution was studied using two types of $\mathrm{TiO}_{2}$ powders with different specific surface areas and dispersed particle sizes as a catalyst, and $\mathrm{HCOOH}$ as a reductant. The principal reduction products were $\mathrm{Se}^{\circ}$ and $\mathrm{H}_{2} \mathrm{Se}$; $\mathrm{Se}$ (IV) was not detected. The reduction rate of $\mathrm{Se}(\mathrm{VI})$ was mainly controlled by the amount of $\mathrm{Se}(\mathrm{VI})$ adsorbed onto each type of the $\mathrm{TiO}_{2}$ powders. When different $\mathrm{TiO}_{2}$ powders were used, the energy conversion ratio of $\mathrm{TiO}_{2}$ played the more important role in the photocatalytic reduction of $\mathrm{Se}(\mathrm{VI})$ or $\mathrm{Se}^{\circ}$. Using a $\mathrm{TiO}_{2}$ catalyst with a high conversion ratio, the time required for the reductions of $\mathrm{Se}(\mathrm{VI})$ to $\mathrm{Se}^{\circ}$ and of $\mathrm{Se}^{\circ}$ to $\mathrm{H}_{2} \mathrm{Se}$ differed by a ratio of $3: 1$, as expected from reaction equations. The reduction rates for $\mathrm{Se}(\mathrm{VI})$ can be approximated from the amount of Se(VI) adsorbed onto $\mathrm{TiO}_{2}$ powders and the energy conversion ratios. The $\mathrm{pH}$ of solution, amount of $\mathrm{TiO}_{2}$ and concentrations of $\mathrm{Se}(\mathrm{VI})$ and $\mathrm{HCOOH}$ were additionaly recognized as important factors.

(Received February 7, 2000; Accepted May 19, 2000)

Keywords: photocatalytic reduction, selenate, selenite, anatase powder

\section{Introduction}

It has been same time since the application of photocatalytic technology utilizing semiconductor powders to industrial and environmental problems has attracted public attention. Among the various photocatalysts, $\mathrm{TiO}_{2}$ is a chemically stable material, which needs ultraviolet light to move electron from the valence band to conduction band, ${ }^{1,2)}$ and is certainly one of the most interesting photocatalysts to be studied.

Although the study of $\mathrm{TiO}_{2}$ as a photocatalyst was initially aimed at the production of hydrogen through the decomposition of water ${ }^{3)}$ and the synthesis of various organic compounds through the reduction of carbon dioxide, ${ }^{4}$ technological interest in recent years has been directed towards applications to clean and restore the environment. Photocatalytic decomposition of harmful organic matter, ${ }^{5)}$ photo-oxidation of air pollutants such as $\mathrm{NO}_{x}$ (nitrogen oxides) and $\mathrm{SO}_{2},{ }^{6)}$ and sterilization to MRSA and mold ${ }^{7)}$ are typical examples. In addition, fundamental studies on the decomposition reaction of harmful materials using photocatalysts, aiming at the control of soil contamination or water pollution caused by industrial discharge ${ }^{8,9)}$ have been actively performed in recent years. Research into the utilization of photocatalysts in the treatment of industrial wastewater and sea water is mainly centered on the photocatalystic decomposition of organic chloride compounds and petroleum out-flow, ${ }^{5)}$ with no significant study having been conducted on the decomposition of harmful inorganic compounds.

Selenium is mainly contained in $\mathrm{SO}_{2}$ gas generated from roaster of sulfidic ore, and thus treatment and recovery from the smelting process of sulfides and the production process of sulfuric acid provide problems to be solved. The re-

\footnotetext{
${ }^{* 1}$ This Paper was originally published in Japanese in J. Japan Inst. Metals, 64 (2000), 34

${ }^{* 2}$ Undergraduate Student, Toyama University.
}

cent introduction of new regulations has made the disposal of wastewater containing selenate or selenite ions more difficult. For example, the effluent standard for Se in Japan is now $0.1 \mathrm{mg} / \mathrm{cm}^{3}$. In regard to this, Kikuchi ${ }^{10)}$ and Sanuki et al. ${ }^{11)}$ examined the possibility of applying $\mathrm{TiO}_{2}$ as a photocatalyst for Se treatment.

The purpose of the present work is to elucidate the role of various factors, including powder characteristics, amount of $\mathrm{TiO}_{2}$ catalyst, $\mathrm{pH}$ of the solution, concentrations of Se ions and $\mathrm{HCOOH}$.

\section{Theoretical Considerations of $\mathrm{Se}(\mathrm{VI})$ Reduction}

In an acidic solution, the state of selenium changes, in the sequence $\mathrm{SeO}_{4}^{2-}$ to $\mathrm{HSeO}_{3}^{-}, \mathrm{Se}^{\circ}$ and $\mathrm{H}_{2} \mathrm{Se}$, with the potential. $^{12)}$

At a low $\mathrm{pH}$, the reduction of selenate to selenite and continuously elemental selenium is expressed by eqs. (1) and (2).

$$
\begin{aligned}
& \mathrm{SeO}_{4}^{2-}+3 \mathrm{H}^{+}+2 \mathrm{e}^{-}=\mathrm{HSeO}_{3}^{-}+\mathrm{H}_{2} \mathrm{O} \\
& E=1.075-0.0886 \mathrm{pH}+0.295 \log \left[\mathrm{SeO}_{4}^{2-}\right] /\left[\mathrm{HSeO}_{3}^{-}\right] \\
& \mathrm{HSeO}_{3}^{-}+5 \mathrm{H}^{+}+4 \mathrm{e}^{-}=\mathrm{Se}^{\circ}+3 \mathrm{H}_{2} \mathrm{O} \\
& E=0.0739-0.0739 \mathrm{pH}+0.148 \log \left[\mathrm{HSeO}_{3}^{-}\right]
\end{aligned}
$$

As mentioned in a previous paper, ${ }^{11)}$ in the reduction of selenate ions by a photocatalytic route, no formation of selenite is detected and selenate is directly reduced to elemental Se, as shown by eq. (3), and under low-pH conditions, $\mathrm{Se}^{\circ}$ is further reduced to $\mathrm{H}_{2}$ Se as given by eq. (4).

$$
\begin{aligned}
& \mathrm{SeO}_{4}^{2-}+8 \mathrm{H}^{+}+6 \mathrm{e}^{-}=\mathrm{Se}^{\circ}+4 \mathrm{H}_{2} \mathrm{O} \\
& E=0.876-0.0788 \mathrm{pH}+0.0099 \log \left[\mathrm{SeO}_{4}^{2-}\right] \\
& \mathrm{Se}^{\circ}+2 \mathrm{H}^{+}+2 \mathrm{e}^{-}=\mathrm{H}_{2} \mathrm{Se} \\
& E=-0.369-0.0591 \mathrm{pH}-0.0295 \log p_{\mathrm{H}_{2} \mathrm{Se}}
\end{aligned}
$$


$\mathrm{TiO}_{2}$ powders are a typical $n$-type semiconductor, and its impurity level is determined either by an oxygen vacancy or an interstitial-impurity $\mathrm{Ti}$ atom. The energy band level of $\mathrm{TiO}_{2}$ is determined by factors such as the particulate size of $\mathrm{TiO}_{2}$ and the $\mathrm{pH}$ of the electrolyte used. ${ }^{10)}$ It is reported that the reduction potential at the edge of a conduction band of $\mathrm{TiO}_{2}$ in an aqueous solution of $\mathrm{pH} 1$ is $0 \mathrm{~V}$ vs NHE. ${ }^{10)}$ Therefore, Reactions (1) to (3) readily proceed on $\mathrm{TiO}_{2}$ surface, whereas Reaction (4) is difficult to induce. With the use of a suitable reductant in the absence of any oxidizing agent, however, the value for conduction-band energy becomes negative. Product gas removal would be possible if an inert gas is bubbled through the reacting suspension and vented. And, as a result, Reaction (4) can proceed.

\section{Experimental Procedures}

\subsection{Catalysts}

In the present study, two different anatase-type $\mathrm{TiO}_{2}$ powders having different specific surface areas and mean particle sizes were used. The BET specific surface area and mean dispersed particle size of sample A were $145 \mathrm{~m}^{2} / \mathrm{g}$ and $10.3 \mu \mathrm{m}$, respectively, while those of sample $\mathrm{B}$, consisting of around $70 \%$ anatase and the rest rutile, were $47.6 \mathrm{~m}^{2} / \mathrm{g}$ and $0.20 \mu \mathrm{m}$, respectively. Figure 1 shows TEM photographs of $\mathrm{TiO}_{2}$ samples used. Sample A is an aggregate of primary fine particles with a uniform size, while sample B comprises ultra fine particles with connections.

\subsection{Reagents and preparation of test solutions}

The reagents used were all of reagent grade and the water was deionized with a specific resistivity of $>5.0 \times 10^{4} \Omega \cdot \mathrm{m}$. Sodium selenate $\left(\mathrm{Na}_{2} \mathrm{SeO}_{4}\right)$ and sodium selenite $\left(\mathrm{Na}_{2} \mathrm{SeO}_{3}\right)$ were used as sources of $\mathrm{Se}$, and $\mathrm{HCOOH}$ was used as a reductant. $\mathrm{Na}_{2} \mathrm{SeO}_{4}$ or $\mathrm{Na}_{2} \mathrm{SeO}_{3}$ was dissolved in deionized water to prepare solutions with suitable Se concentrations rang- ing $50 \sim 200 \mathrm{ppm}$. The $\mathrm{pH}$ of test solutions was adjusted to 3, 4 and 5 with aqueous $\mathrm{NaOH}$ solution in case of need. $\mathrm{Na}_{2} \mathrm{SO}_{4}$ was used to examine the suppression effect on the reduction of $\mathrm{Se}(\mathrm{VI})$. The role of $\mathrm{HCOOH}$ is to prevent the re-oxidation of reduced material. The $\mathrm{HCOOH}$ concentration during the reaction was adjusted in the range $1.0 \times 10^{-2}$ to $5.0 \times 10^{-2} \mathrm{kmol} / \mathrm{m}^{3}$.

\subsection{Photocatalytic reduction of test solutions}

The assembly of the experimental apparatus, consisting of pure water reservoir to prevent the evaporation of the Se(VI) solution during the reaction, a photocatalytic reactor and traps for exhaust gas is schematically illustrated in Fig. 2. Ten $20 \mathrm{~W}$ BLB fluorescent lamps made by Toshiba were used as a source of ultraviolet (UV) light. Light was irradiated from the side of the reactor. The intensity of BLB fluorescence was strongest at a wavelength of $352 \mathrm{~nm}$, and enough to excite $\mathrm{TiO}_{2}$ catalyst. The experimental apparatus was set inside

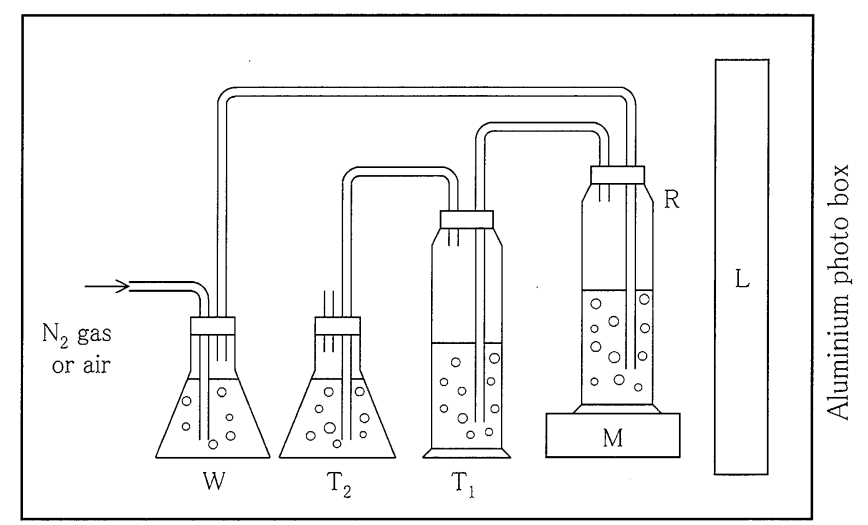

Fig. 2 Schematic illustration of the experimental apparatus used for the photocatalytic reduction of Se(VI). L: BLB UV Lamps, R: Reactor, M: Magnetic stirrer, W: Water, $\mathrm{T}_{1}$ : Trap for $\mathrm{H}_{2} \mathrm{Se}\left(5 \times 10^{-3} \mathrm{kmol} / \mathrm{m}^{3} \mathrm{CuSO}_{4}\right)$, $\mathrm{T}_{2}$ : Trap for $\mathrm{H}_{2} \mathrm{Se}\left(1 \times 10^{-3} \mathrm{kmol} / \mathrm{m}^{3} \mathrm{NaOH}\right)$.

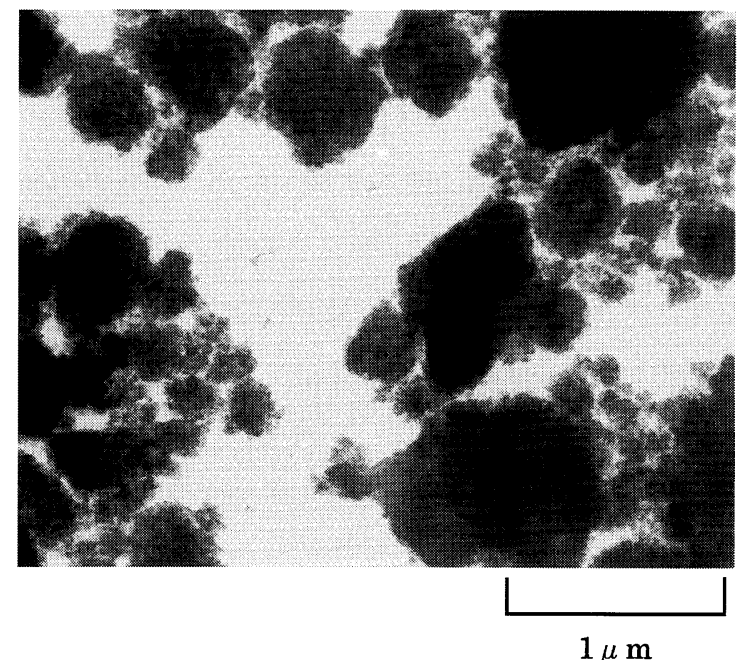

(a) $\mathrm{TiO}_{2}$ Sample $\mathrm{A}$

(anatase, SSA: $145 \mathrm{~m}^{2} / \mathrm{g}, \mathrm{d}_{\mathrm{av}}: 1.0 \mu \mathrm{m}$ )

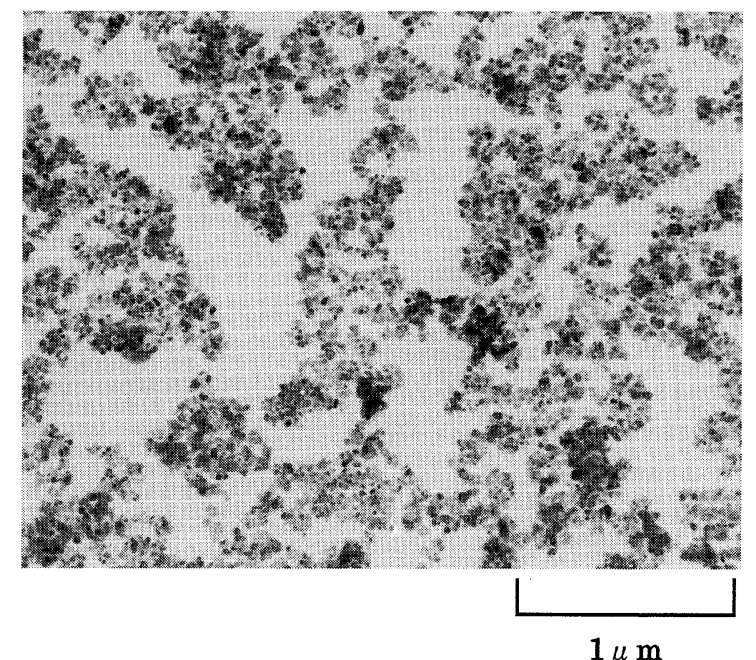

(b) $\mathrm{TiO}_{2}$ Sample B

(anatase $70 \%$, SSA: $47.6 \mathrm{~m}^{2} / \mathrm{g}, \mathrm{d}_{\mathrm{av}}: 0.2 \mu \mathrm{m}$ )

Fig. 1 TEM micrographs of the $\mathrm{TiO}_{2}$ photocatalyst used. 
an aluminum box, $50 \times 60 \times 80 \mathrm{~cm}^{3}$, and the intensity of UV light was kept at 54 or $48 \mathrm{~W} / \mathrm{m}^{2}$. A volume of $100 \mathrm{~cm}^{3}$ of test solution was placed in a glass cylindrical reactor (a Muencktype gas wash bottle was used for the photocatalytic reactor) with $250 \mathrm{~cm}^{3}$ capacity, into which $0.11 \mathrm{~g}$ of $\mathrm{TiO}_{2}$ powder was dispersed with the aid of a magnetic stirrer. The test solution was de-oxygenated by bubbling with $\mathrm{N}_{2}$ gas for $1.8 \mathrm{ks}$. The photocatalytic reduction experiment was initiated by UV light irradiation. Exhaust gas was passed through two traps in series, containing $5 \times 10^{-3} \mathrm{kmol} / \mathrm{m}^{3} \mathrm{CuSO}_{4}$ and $0.1 \mathrm{kmol} / \mathrm{m}^{3}$ $\mathrm{NaOH}$ to remove $\mathrm{H}_{2} \mathrm{Se}$. After a predetermined period, a sample aliquot was taken to separate solution from $\mathrm{TiO}_{2}$ and $\mathrm{Se}^{\circ}$ by a centrifugal separator for quantitative analyses.

\subsection{Adsorption isotherm determination of Se ions on $\mathrm{TiO}_{2}$}

Aqueous solutions containing $\mathrm{Na}_{2} \mathrm{SeO}_{4}$ or $\mathrm{Na}_{2} \mathrm{SeO}_{3}$, with an Se concentration ranging from 5 to $100 \mathrm{ppm}$ and a $\mathrm{HCOOH}$ concentration of $2.5 \times 10^{-2} \mathrm{kmol} / \mathrm{m}^{3}$, were subjected to adsorption isotherm experiments. Twenty $\mathrm{cm}^{3}$ of Se solution thus prepared was taken in a centrifugal tube, and $1.1 \mathrm{~kg} / \mathrm{m}^{3}$ of $\mathrm{TiO}_{2}$ powder was added to it. Experiments were conducted at $293 \pm 1 \mathrm{~K}$ by shaking the tube for $1.8 \mathrm{ks}$ to attain a state of equilibrium. After removal of the $\mathrm{TiO}_{2}$ powder from the solution with a centrifugal separator, the Se concentration of the resultant solution was determined. The amount of Se ions on the $\mathrm{TiO}_{2}$ powder was calculated as the difference between the initial concentration of ions and the concentration in the state of equilibrium. In determination isotherms, blanks were used to ensure that there was no adsorption on the wall of the centrifugal tube.

\subsection{Analysis}

After irradiation with UV light, $\mathrm{TiO}_{2}$ powders and precipitates were separated from the solutions by the centrifugal separator. The total Se remaining in solution was determined using a hydride generator and an atomic absorption spectrophotometer, and the selenate and selenite concentrations were analyzed by ion chromatography. The amount of $\mathrm{H}_{2}$ Se generated was determined from the amount of $\mathrm{Cu}$ (II) remaining in the $\mathrm{CuSO}_{4}$ trap. Precipitates generated and the $\mathrm{TiO}_{2}$ were filtered in vacuo and rinsed with water, then subjected to the analyses of elemental $\mathrm{Se}$ and $\mathrm{Se}$ ions adsorbed by $\mathrm{TiO}_{2}$ powders. The Se ions adsorbed onto $\mathrm{TiO}_{2}$ powders were washed with sodium carbonate solutions to desorb them from the $\mathrm{TiO}_{2}$ surface, and the obtained solution was subjected to chemical analysis to estimate the amount of adsorbed Se. The elemental $\mathrm{Se}$ in the washing residue was dissolved with nitric acid $^{13)}$ and the Se ion concentration was determined after removing the $\mathrm{TiO}_{2}$ powders.

\section{Experimental Results and Discussion}

\subsection{Effect of Se adsorbed onto $\mathrm{TiO}_{2}$ catalyst on the pho- tocatalytic reduction of Se ions}

As mentioned previously, ${ }^{11)}$ the photocatalytic reduction of $\mathrm{Se}$ (VI) or Se(IV) will not proceed without the addition of a suitable reductant for the prohibition of the re-oxidation of reduced products and the irradiation of UV light. In a pre- vious paper, we mentioned that the decrease in concentration of $\mathrm{Se}(\mathrm{VI})$ or $\mathrm{Se}(\mathrm{IV})$ observed without UV irradiation is attributed to the adsorption of these ions onto $\mathrm{TiO}_{2}$ powders.

On the other hand, it is considered that the mechanism of photocatalytic reaction is based on the delivery and receipt of electrons between excited $\mathrm{TiO}_{2}$ and Se ions adsorbed onto $\mathrm{TiO}_{2}$ catalyst.

Figure 3 shows the adsorption isotherm determined for $\mathrm{Se}(\mathrm{VI})$ or $\mathrm{Se}(\mathrm{IV})$ on anatase type $\mathrm{TiO}_{2}$ powders without UV irradiation.

With sample A, adsorption of Se(VI) was saturated at about $10 \mathrm{mg} / \mathrm{g}$, a value which decreased by around half on addition of $5 \times 10^{-3} \mathrm{kmol} / \mathrm{m}^{3} \mathrm{Na}_{2} \mathrm{SO}_{4}$, the $\mathrm{Se}(\mathrm{VI})$ adsorption sites being replaced by $\mathrm{SO}_{4}^{2-}$ ions.

The adsorption isotherm of Se(IV) for sample $\mathrm{A}$ is also depicted on Fig. 3. As is clear from this figure, the amount of $\mathrm{Se}(\mathrm{IV})$ adsorbed is around 2.5 times that of Se(VI). Figure 3 also shows that the adsorption isotherm of $\mathrm{Se}(\mathrm{VI})$ for sample $\mathrm{B}$, was slightly less than half the value for sample A.

\subsection{Photocatalytic reduction of $\mathrm{Se}(\mathrm{VI})$ and $\mathrm{Se}(\mathrm{IV})$ with sample A}

Figure 4(a) shows the rate curves of photocatalytic reduction of $\mathrm{Se}$ (VI) with sample A. As is obvious from this figure, the time required to reach the peak, which corresponds to slightly more than $80 \%$ of elemental $\mathrm{Se}^{\circ}$ formation, is $5.4 \mathrm{ks}$, and the time for the completion of $\mathrm{H}_{2} \mathrm{Se}$ generation is about $9.0 \mathrm{ks}$. It is noteworthy that no Se(IV) was detected as an intermediate product. The color of the $\mathrm{TiO}_{2}$ powders after the generation of $\mathrm{H}_{2} \mathrm{Se}$ was slightly grayish. It is supposed that a small amount of elemental $\mathrm{Se}^{\circ}$ precipitated inside the $\mathrm{TiO}_{2}$ aggregate causes this color change.

Figure 4(c) shows the experimental results obtained for the reduction, which was performed under the same conditions as for Fig. 4(a), except that $\mathrm{Se}(\mathrm{IV})$ was replaced with $\mathrm{Se}(\mathrm{VI})$. The maximum yield of elemental $\mathrm{Se}^{\circ}$ was a little over $75 \%$, and the time required to reach the peak position was $1.8 \mathrm{ks}$, which corresponds to only around $1 / 3$ the time for $\mathrm{Se}(\mathrm{VI})$. After $7.2 \mathrm{ks}$, the starting species was completely decomposed, but elemental $\mathrm{Se}^{\circ}$ remained with a few percents in the solu-

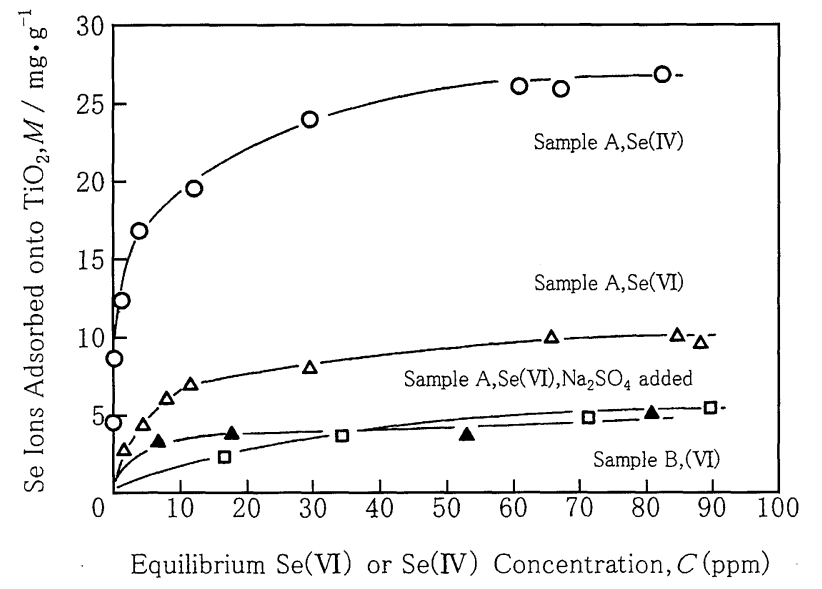

Fig. 3 Adosorption isotherms of $\mathrm{Se}(\mathrm{VI})$ or $\mathrm{Se}(\mathrm{IV})$ onto $\mathrm{TiO}_{2}$ powders without UV irradiation. Temperature: $293 \pm 1 \mathrm{~K}, \mathrm{TiO}_{2}: 1.1 \mathrm{~kg} / \mathrm{m}^{3}$, agitation time: $1.8 \mathrm{ks}, \mathrm{HCOOH}: 2.5 \times 10^{-2} \mathrm{kmol} / \mathrm{m}^{3}, \mathrm{Na}_{2} \mathrm{SO}_{4}: 5 \times 10^{-3} \mathrm{kmol} / \mathrm{m}^{3}$. 


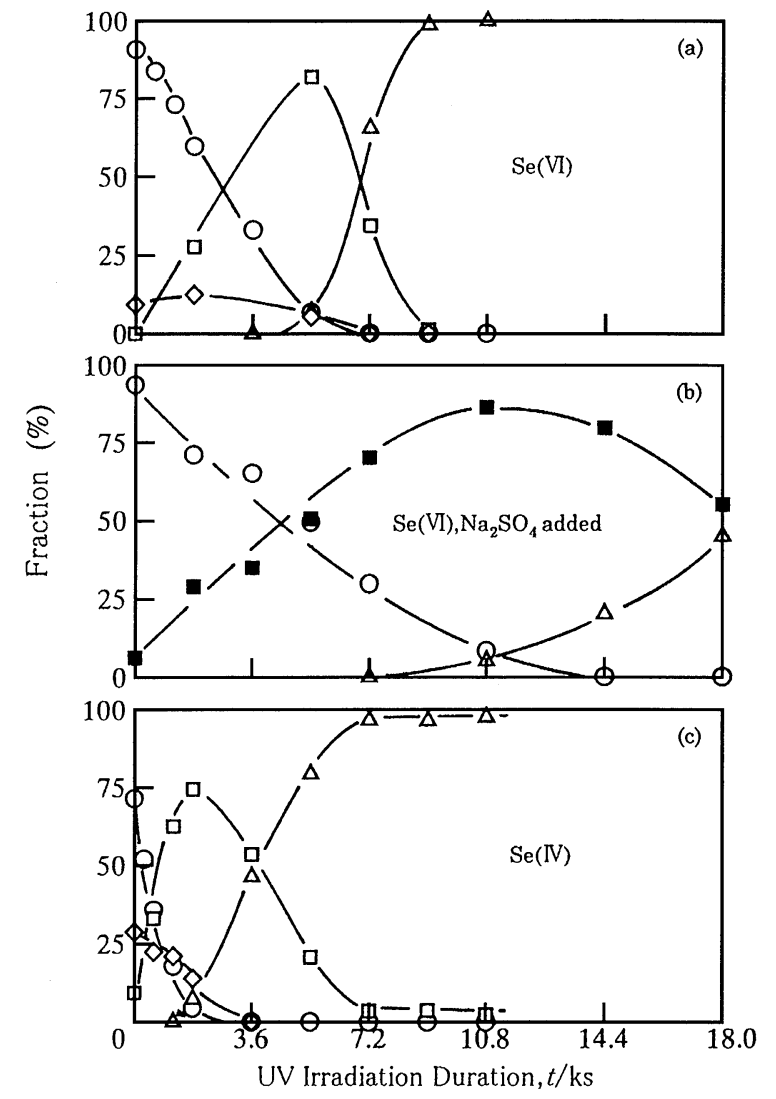

Fig. 4 Rate curves of photocatalytic reduction of Se(VI) specify in the absence (a) and the presence of $\mathrm{Na}_{2} \mathrm{SO}_{4}$ (b) and those of $\mathrm{Se}$ (IV) (c). (a), (c) Total Se concentration: $100 \mathrm{ppm}$, reductant: $2.5 \times 10^{-2} \mathrm{kmol} / \mathrm{m}^{3}$ $\mathrm{HCOOH}$, catalyst sample A: $1.1 \mathrm{~kg} / \mathrm{m}^{3} \mathrm{TiO}_{2}, \mathrm{~N}_{2}$ gas bubbling, UV irradiation: $54 \mathrm{~W} / \mathrm{m}^{2}, \bigcirc$ : Se ions in solution, $\square: \mathrm{Se}^{\circ}, \diamond$ : Se ions absorbed on $\mathrm{TiO}_{2}, \triangle: \mathrm{H}_{2} \mathrm{Se}\left(\right.$ b) $\mathrm{Na}_{2} \mathrm{SO}_{4}$ added: $5 \times 10^{-3} \mathrm{kmol} / \mathrm{m}^{3}, \mathbf{\square}: \mathrm{Se}^{\circ}$ and $\mathrm{Se}$ ions absorbed on $\mathrm{TiO}_{2}$, Other experimental conditions and symbols used are the same as (a) and (c).

tion. However, red $\mathrm{Se}^{\circ}$ having characteristic of amorphous, was changed to gray. The time required to attain the stable state with no more reduction of $\mathrm{Se}^{\circ}$ was $5.4 \mathrm{ks}$ from the time at the peak.

The reduction from elemental $\mathrm{Se}^{\circ}$ to $\mathrm{H}_{2} \mathrm{Se}$ took longer than for $\mathrm{Se}(\mathrm{VI})$.

As can be seen from Fig. 3, the amount of Se(IV) adsorbed is about 2.5 times larger than that of $\mathrm{Se}$ (VI). Since the photocatalytic reaction proceeds on the surface of the catalyst, and 1.5 more electrons are required for the reduction of $\mathrm{Se}(\mathrm{IV})$ to $\mathrm{Se}^{\circ}$ than $\mathrm{Se}^{\circ}$ to $\mathrm{H}_{2} \mathrm{Se}$ according to the reaction eqs. (2) and (4), it is reasonable that the time required for reduction would decrease. The fact that $\mathrm{Se}^{\circ}$ was not perfectly reduced to $\mathrm{H}_{2} \mathrm{Se}$ may be attributed to less photocatalytic reduction on the catalyst surface due to a partial change in the $\mathrm{Se}^{\circ}$ structure.

If the reduction site on the catalyst is occupied by difficultto-reduce species, the reaction rate should be decreased.

Figure 4(b) depicts the reduction rate curves for $\mathrm{Se}(\mathrm{VI})$ obtained in the presence of $5 \times 10^{-3} \mathrm{kmol} / \mathrm{m}^{3} \mathrm{Na}_{2} \mathrm{SO}_{4}$. In this figure, the mark $\mathbf{D}$ shows the value which calculated by subtracting the sum of residual $\mathrm{Se}$ (VI) concentration and the amount of $\mathrm{H}_{2} \mathrm{Se}$ formed from the initial concentration of $\mathrm{Se}(\mathrm{VI})$; it corresponds to the $\mathrm{Se}^{\circ}$ formed including the several $\%$ of $\mathrm{Se}(\mathrm{VI})$ adsorbed. Under the experimental conditions, the amount of $\mathrm{Se}(\mathrm{VI})$ adsorbed is around a half that in the absence of $\mathrm{Na}_{2} \mathrm{SO}_{4}$, as depicted in Fig. 3. The time required to reach the peak position for the reduction of $\mathrm{Se}$ (IV) to $\mathrm{Se}^{\circ}$ is doubled, $10.8 \mathrm{ks}$, as anticipated. When the adsorption of $\mathrm{SeO}_{4}^{2-}$ ions was controlled with $\mathrm{SO}_{4}^{2-}$ ions, the reduction of $\mathrm{Se}$ (VI) was terminated at $14.4 \mathrm{ks}$. Although the graphical presentation was omitted, several mass percent of $\mathrm{Se}^{\circ}$ remained in the reaction system without further reduction at $21.6 \mathrm{ks}$, after the reaction system reached a stable state. This phenomenon is also evident from the liberation of $\mathrm{Se}^{\circ}$ from the surface of the catalyst and the change in the color of $\mathrm{Se}^{\circ}$ to gray.

\subsection{Photocatalytic reduction of $\mathrm{Se}(\mathrm{VI})$ with sample $\mathrm{B}$ $\mathrm{TiO}_{2}$}

Figures 5(a) and (b) show the respective rate curves of $\mathrm{Se}(\mathrm{VI})$ reduction using samples $\mathrm{A}$ and $\mathrm{B}$ under the same conditions listed in the caption. As can be seen in these figures, the peak position of $\mathrm{Se}^{\circ}$ at which yields were both $82 \%$ was observed when $7 \%$ of Se(VI) for sample A and $15 \%$ for sample $B$ remain in the solutions. The time required to reach the peak position of $\mathrm{Se}^{\circ}$ formation was $5.4 \mathrm{ks}$ with sample $\mathrm{A}$ and $4.5 \mathrm{ks}$ with sample B. The time required for completion of the reaction of $\mathrm{Se}^{\circ}$ to $\mathrm{H}_{2} \mathrm{Se}$ was $3.6 \mathrm{ks}$ for the former case and $1.5 \mathrm{ks}$ for the latter. As is indicated by eqs. (3) and (4), 6 electrons are required to reduce $\mathrm{Se}(\mathrm{VI})$ to $\mathrm{Se}^{\circ}$ and 2 electrons to reduce $\mathrm{Se}^{\circ}$ to $\mathrm{H}_{2} \mathrm{Se}$. When sample $\mathrm{B}$ was used as a catalyst, the time required for $\mathrm{Se}^{\circ}$ formation and that for the reduction of $\mathrm{Se}^{\circ}$ to $\mathrm{H}_{2} \mathrm{Se}$ satisfied the requirement of the electron ratio for these reactions. As already mentioned, the time required for the reduction of $\mathrm{Se}(\mathrm{VI})$ and of $\mathrm{Se}(\mathrm{IV})$ to $\mathrm{Se}^{\circ}$ with sample A can be roughly anticipated from the adsorption amount and electron conversion ratio. From the adsorption isotherm curves for $\mathrm{Se}(\mathrm{VI})$, the amount of $\mathrm{Se}(\mathrm{VI})$ adsorbed on sample B is found to be around $50 \%$ less than that for sample A

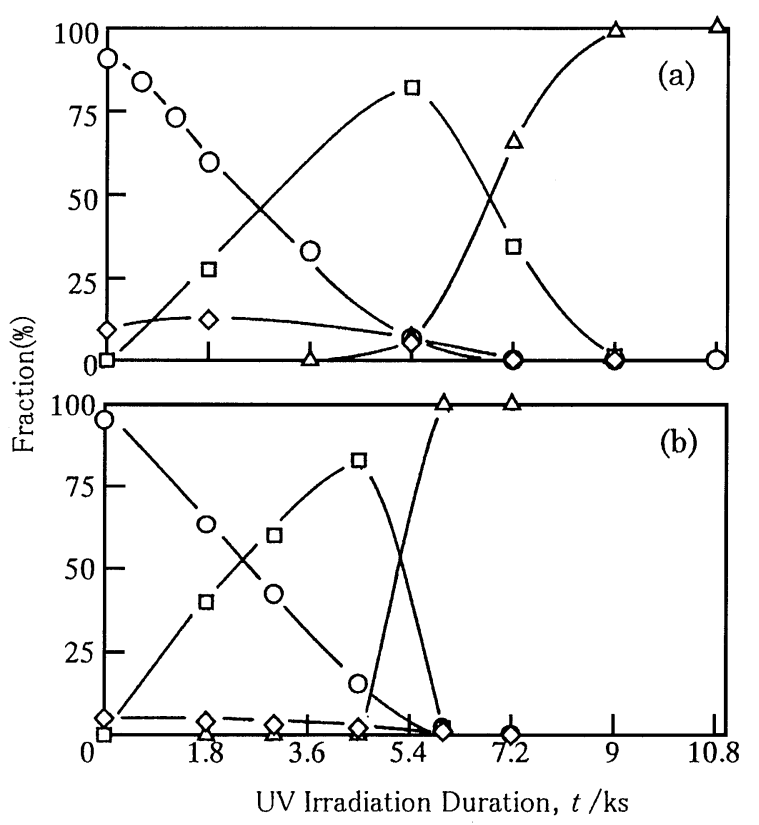

Fig. 5 Rate curves of the photocatalytic reduction of $\mathrm{Se}(\mathrm{VI})$ using catalyst sample $\mathrm{A}$ (a) and $\mathrm{B}$ (b). [Se(VI)]: $100 \mathrm{ppm},[\mathrm{HCOOH}]$ : $2.5 \times 10^{-2} \mathrm{kmol} / \mathrm{m}^{3}, \mathrm{TiO}_{2}$ used: $1.1 \mathrm{~kg} / \mathrm{m}^{3}, \mathrm{~N}_{2}$ gas bubbling, UV irradiation: $54 \mathrm{~W} / \mathrm{m}^{2}$. 
as shown in Fig. 3. This result differs from the finding that the photocatalytic reduction rate is determined by adsorption amount of reductant, which is the finding obtained with sample A.

Considering the time required for reduction using sample B under the present experimental conditions, the energy converted by UV irradiation is efficient for the formation of elemental Se, and that of $\mathrm{H}_{2} \mathrm{Se}$ as well. Therefore, the energy conversion ratios for both reactions are the same.

Regarding the reduction of $\mathrm{Se}^{\circ}$ to $\mathrm{H}_{2} \mathrm{Se}$, it is unnecessary to consider the adsorption of $\mathrm{Se}(\mathrm{VI})$ and $\mathrm{Se}(\mathrm{IV})$ onto $\mathrm{TiO}_{2}$. The peak percent values for the two samples are almost the same, so that the time required for the formation of $\mathrm{H}_{2} \mathrm{Se}$ with sample A should be $1.5 \mathrm{ks}$, as with sample B. However, the actual time was $3.6 \mathrm{ks}$, which means that the energy conversion ratio is $42 \%$ of that with sample B.

Assuming that this finding is appropriate and considering the difference in amount of $\mathrm{Se}(\mathrm{VI})$ adsorbed by the sample catalysts, the time required for the reduction of $\mathrm{Se}(\mathrm{VI})$ to elemental Se with sample A can be estimated by dividing the product of the time required for the reduction of $\mathrm{Se}^{\circ}$ to $\mathrm{H}_{2} \mathrm{Se}$ with sample B $(1.5 \mathrm{ks})$ and the electrons required for the reduction $(6 / 2=3)$ with the product of energy conversion ratio (0.42) and the adsorption amount ratio with sample A against those with sample B (2.0).

The time required for the reduction of $\mathrm{Se}(\mathrm{VI})$ to $\mathrm{Se}^{\circ}$, thus calculated, is $5.36 \mathrm{ks}$, which coincides well with the value of $5.4 \mathrm{ks}$ shown in Fig. 5(a).

The difference obtained using different samples of photocatalyst can be explained as follows.

The specific surface area of sample A is $145 \mathrm{~m}^{2} / \mathrm{g}$, which is around 3 times that of sample $B$, but the mean particle size of sample B is far smaller than that of sample A as can be seen from the photographs shown in Fig. 1. Judging from these values, we can assume that the porous structure of sample A results in an increase in specific surface area, and more $\mathrm{Se}$ (VI) is adsorbed than by sample $B$, and this finding is reasonable in view of the difference in specific surface area.

On the other hand, the mass transfer of reactant and reaction product from inside the pore of particles to the bulk phase is anticipated to be small, and furthermore, the transmission ability of UV light to the inside of the pore is poor. Thus the energy conversion of sample $B$, which has finer particles than sample A, is thought to proceed effectively under the experimental conditions of this study.

Photocatalytic particles are sometimes fixed in a binder. In such cases, it is necessary to expose the photocatalytic particles. However, this is difficult with extremely fine particles. It is important to select a suitable photocatalyst.

\subsection{Effect of various factors on the photocatalytic reduc- tion of $\mathrm{Se}(\mathrm{VI})$ to $\mathrm{Se}^{\circ}$}

In Section 3, we mentioned that the reduction effect is more remarkable with sample B than sample A under the present experimental conditions, and this phenomenon is attributable to the difference in energy conversion ratio due to the difference in mean particle size of the photocatalyst. As another reason, we should consider the change in the level of the energy band of $\mathrm{TiO}_{2}$ caused by the $\mathrm{pH}$ of the solution, and the re- combination of positive holes and adjacent electrons on $\mathrm{TiO}_{2}$ particles under the excited conditions. Thus, the effects of solution $\mathrm{pH}$, concentrations of $\mathrm{HCOOH}$ and $\mathrm{Se}(\mathrm{VI})$ and amount of photocatalysts upon reduction of $\mathrm{Se}(\mathrm{VI})$ ions were also investigated.

\subsubsection{Effect of initial $\mathrm{pH}$ of $\mathrm{Se}(\mathrm{VI})$ solution}

Figures 6 and 7 show the time variations of photocatalytic reduction of $\mathrm{Se}(\mathrm{VI})$ with $\mathrm{UV}$ irradiation duration at $\mathrm{pH}$ values of 3,4 and 5 , with samples $A$ and $B$, respectively. The ordinate of these figures is the difference of initial concentration of $\mathrm{Se}(\mathrm{VI})$ and that after the reaction. This value corresponds to the amount $\mathrm{Se}^{\circ}$ formed. However, it actually includes the amount of $\mathrm{Se}(\mathrm{VI})$ adsorbed onto $\mathrm{TiO}_{2}$. In the present study, each factor was evaluated without subtracting adsorption amount.

In all cases, red $\mathrm{Se}^{\circ}$ was formed on irradiation with UV light, and the amount of $\mathrm{Se}^{\circ}$ increased with the increase in irradiation period, while the reaction amount also increased. In contrast, the $\mathrm{pH}$ of the test solution was raised with the increase in irradiation time and reaction amount. For the $\mathrm{Se}(\mathrm{VI})$ solution whose initial $\mathrm{pH}$ was 5 the reaction stopped at 30 ppm Se(VI) with sample A, compared with 10 ppm Se(VI) with sample $\mathrm{B}$, raising the $\mathrm{pH}$ value for both solutions above 7. From these findings, it was concluded that the reduction of $\mathrm{Se}(\mathrm{VI})$ to Se results in the increase in $\mathrm{pH}$, indicating that the reaction proceeded according to eq. (3), which is eqs. (1) and (2) combined. Also, we know that no reduction of $\mathrm{Se}(\mathrm{VI})$ to Se can occur above $\mathrm{pH}$ 7. When the solution $\mathrm{pH}$ with sample $\mathrm{A}$ is compared at the same reduction level to that with sample $\mathrm{B}$, the latter's $\mathrm{pH}$ is higher.

To compare the reduction rates with both sample catalysts, the invert of the time taken for the reaction amount to reach
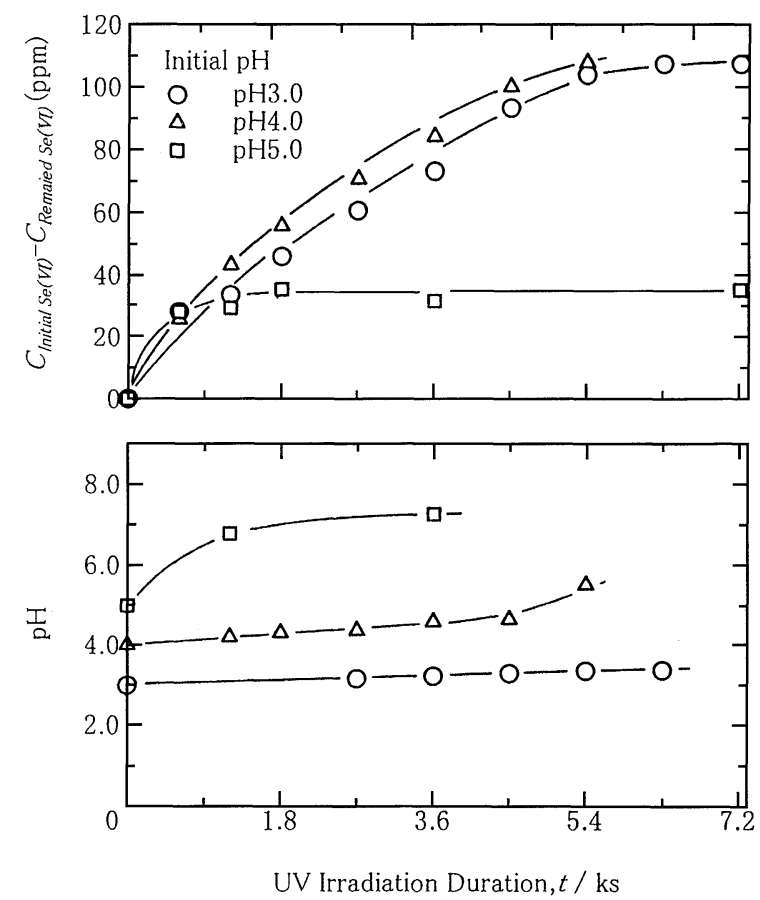

Fig. 6 Effect of initial $\mathrm{pH}$ on rate curves for the photocatalytic reduction of Se(VI) using sample A catalyst. [Se(VI)]: $100 \mathrm{ppm},[\mathrm{HCOOH}]$ $2.5 \times 10^{-2} \mathrm{kmol} / \mathrm{m}^{3}, \mathrm{TiO}_{2}$ used: $1.1 \mathrm{~kg} / \mathrm{m}^{3}, \mathrm{~N}_{2}$ gas bubbling, UV irradiation: $48 \mathrm{~W} / \mathrm{m}^{2}$. 

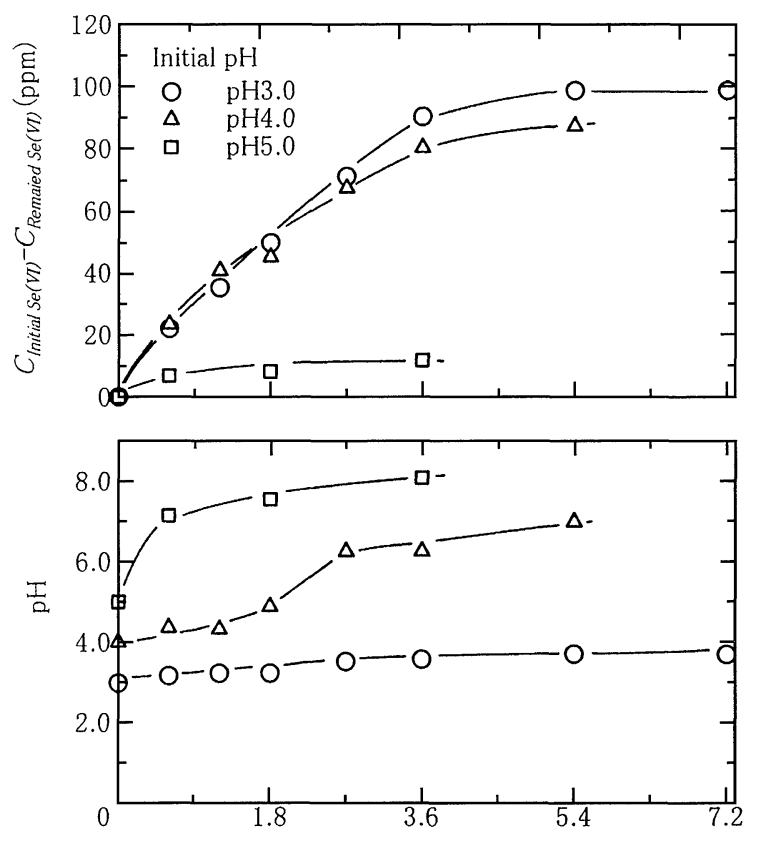

UV Irradiation Duration, $t / \mathrm{ks}$

Fig. 7 Effect of initial $\mathrm{pH}$ on rate curves for the photocatalytic reduction of $\mathrm{Se}(\mathrm{VI})$ using sample B catalyst. [Se(VI)]: $100 \mathrm{ppm},[\mathrm{HCOOH}]$ : $2.5 \times 10^{-2} \mathrm{kmol} / \mathrm{m}^{3}, \mathrm{TiO}_{2}$ used: $1.1 \mathrm{~kg} / \mathrm{m}^{3}, \mathrm{~N}_{2}$ gas bubbling, UV irradiation: $48 \mathrm{~W} / \mathrm{m}^{2}$.

$50 \mathrm{ppm}$ was employed to calculate their mean reaction rate $\bar{R}_{50}$, and the relationship between $\bar{R}_{50}$ and $\mathrm{pH}$ was examined. With sample $B$, the reaction rate stayed a constant value of $5.6 \times 10^{-4} \mathrm{~s}^{-1}$ even when the solution $\mathrm{pH}$ changed from 3 to 4 , whereas the reaction rate at $\mathrm{pH} 3$ with sample $\mathrm{A}$ was $4.7 \times 10^{-4} \mathrm{~s}^{-1}$ and that at $\mathrm{pH} 4$ was $6.7 \times 10^{-4} \mathrm{~s}^{-1}$. However, the difference between samples $\mathrm{A}$ and $\mathrm{B}$ is not significant.

Figure 8 illustrates the effect of $\mathrm{pH}$ on $\mathrm{Se}(\mathrm{VI})$ adsorption by $\mathrm{TiO}_{2}$ catalyst. The amount of $\mathrm{Se}(\mathrm{VI})$ adsorbed by sample A, whose specific surface area is greater than that of sample $B$, is larger than that by sample B. However, this amount decreases with the increase in $\mathrm{pH}$ regardless of which sample catalyst was used.

By raising the solution $\mathrm{pH}$ from 3 to 4 , the amount of $\mathrm{Se}(\mathrm{VI})$ adsorbed on the catalysts was reduced significantly, but the rate of reduction showed no significant change when sample B was used. In contrast, the rate with sample A increased slightly. Therefore, it is suggested that not only adsorption in the control catalytic reaction, but also the driving force is increased by the shift in the energy band level of $\mathrm{TiO}_{2}$ in the minus direction due to the increase of $\mathrm{pH}$ of the test solution.

\subsubsection{Effect of the amount of catalyst}

Next, the effect of catalyst amount on reduction of Se(VI) to $\mathrm{Se}^{\circ}$ was examined. The amount of $\mathrm{Se}(\mathrm{VI})$ reacted and $\mathrm{pH}$ variation were determined by changing the amount of catalyst under the conditions of a $\mathrm{HCOOH}$ concentration of $2.5 \times 10^{-2} \mathrm{kmol} / \mathrm{m}^{3}$, initial Se(VI) concentration of $100 \mathrm{ppm}$, initial $\mathrm{pH}$ of 4 , and UV light irradiation period of $1.8 \mathrm{ks}$. The amount reacted increased with catalyst amount up to $1.5 \mathrm{~kg} / \mathrm{m}^{3}$, but no further, with sample B. By contrast, the re-

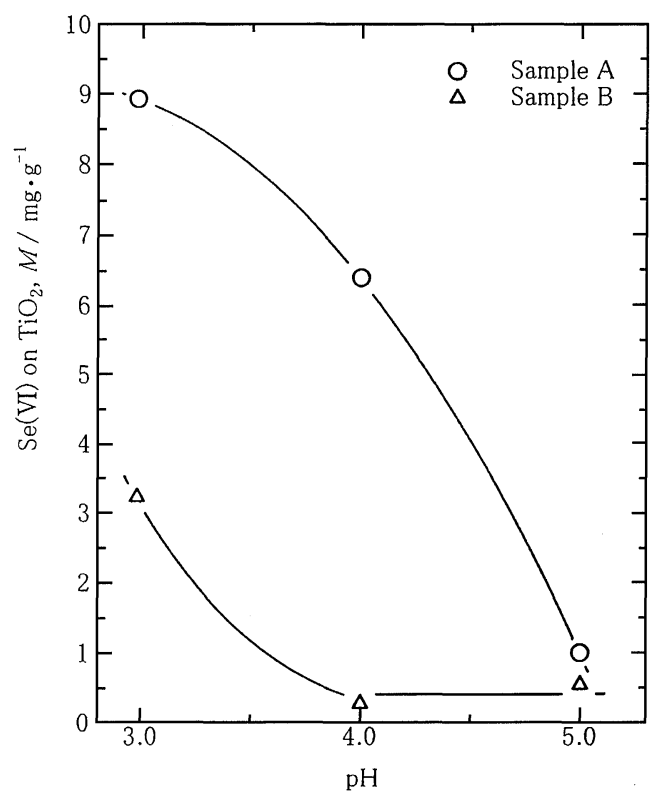

Fig. 8 Effect of $\mathrm{pH}$ on adsorption of $\mathrm{Se}(\mathrm{VI})$. Room temperature, $\mathrm{TiO}_{2}$ used: $1.1 \mathrm{~kg} / \mathrm{m}^{3}$, agitation time: $1.8 \mathrm{ks},[\mathrm{Se}(\mathrm{VI})]: 100 \mathrm{ppm},[\mathrm{HCOOH}]$ : $2.5 \times 10^{-2} \mathrm{kmol} / \mathrm{m}^{3}, \mathrm{pH}$ control: $\mathrm{NaOH}$.

action amount increased with catalyst amount up to $1.1 \mathrm{~kg} / \mathrm{m}^{3}$ but then decreased slightly, with sample $A$. On the other hand, the $\mathrm{pH}$ was raised more with sample B which brought a larger reduction in the amount than that with sample $\mathrm{A}$, and increased with the increase in reduction amount for both catalyst samples. The effect of the amount of catalyst on the reaction rate may also be influenced by the dispersibility of catalyst.

\subsubsection{Effect of formic acid concentration}

The variation in amount reacted and solution $\mathrm{pH}$ with time were determined by changing the formic acid concentration in the test $\mathrm{Se}(\mathrm{VI})$ solution to $1.0,2.5$ and $5.0 \times 10^{-2} \mathrm{kmol} / \mathrm{m}^{3}$ using both catalysts $\mathrm{A}$ and $\mathrm{B}$. With both catalysts, the rate of decrease in $\mathrm{Se}$ (VI) concentration was smaller when $1.0 \times 10^{-2} \mathrm{kmol} / \mathrm{m}^{3}$ rather than $2.5 \times 10^{-2} \mathrm{kmol} / \mathrm{m}^{3}$ or more $\mathrm{HCOOH}$ was used. On the other hand, the tendency for the $\mathrm{pH}$ to increase was more remarkable with sample B than A, when the formic acid concentration was low.

Figure 9 shows the plots of mean reduction rate vs formic acid concentration. The reductive rate was calculated from the time required for $\mathrm{Se}(\mathrm{VI})$ to be reduced to $50 \mathrm{ppm}$. The rate increases with the $\mathrm{HCOOH}$ concentration, showing a constant value above $2.5 \times 10^{-1} \mathrm{kmol} / \mathrm{m}^{3} \mathrm{HCOOH}$. Initial $\mathrm{pH}$ values of $\mathrm{Se}(\mathrm{VI})$ solutions were adjusted to 3 , at which $\mathrm{pH}$ the rate of reduction is slightly larger with sample $B$ than $A$.

\subsubsection{Effect of initial $\mathrm{Se}$ (VI) concentration}

Using both sample catalysts, reduction rates for Se(VI) solution were measured by changing initial Se(VI) concentrations to 50,100 and $200 \mathrm{ppm}$. With sample $\mathrm{A}$, the rate tended to decrease in the sequence of the initial Se(VI) concentration of 100,50 and $200 \mathrm{ppm}$. With sample B, these solutions whose initial $\mathrm{Se}(\mathrm{VI})$ concentrations were 50 and $100 \mathrm{ppm}$, showed a similar rate of reduction until the reaction amount reached $50 \mathrm{ppm}$, but the reduction of $\mathrm{Se}(\mathrm{VI})$, whose concentration was $200 \mathrm{ppm}$ was slow. Also, the reduction of $\mathrm{Se}(\mathrm{VI})$ 


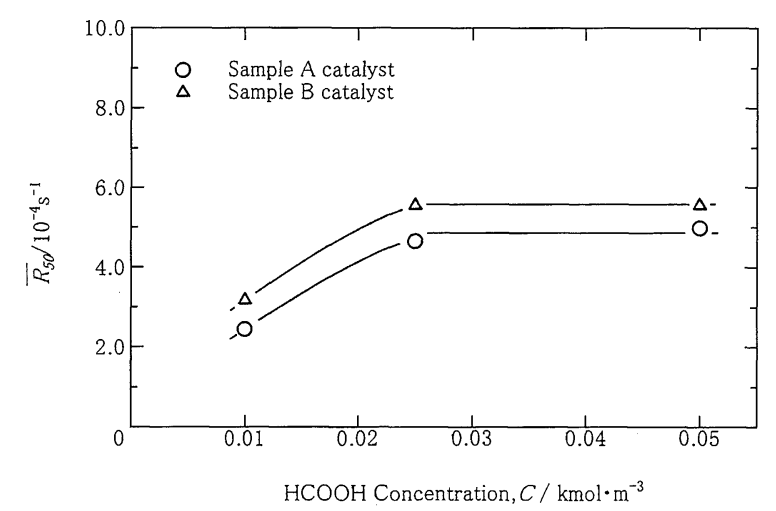

Fig. 9 Effect of $\mathrm{HCOOH}$ on $\bar{R}_{50}$ for the photocatalytic reduction of $\mathrm{Se}(\mathrm{VI})$. [Se(VI)]: 100 ppm, initial $\mathrm{pH}: 3.0, \mathrm{TiO}_{2}$ used: $1.1 \mathrm{~kg} / \mathrm{m}^{3}, \mathrm{~N}_{2}$ gas bubbling, UV irradiation: $48 \mathrm{~W} / \mathrm{m}^{2}$.

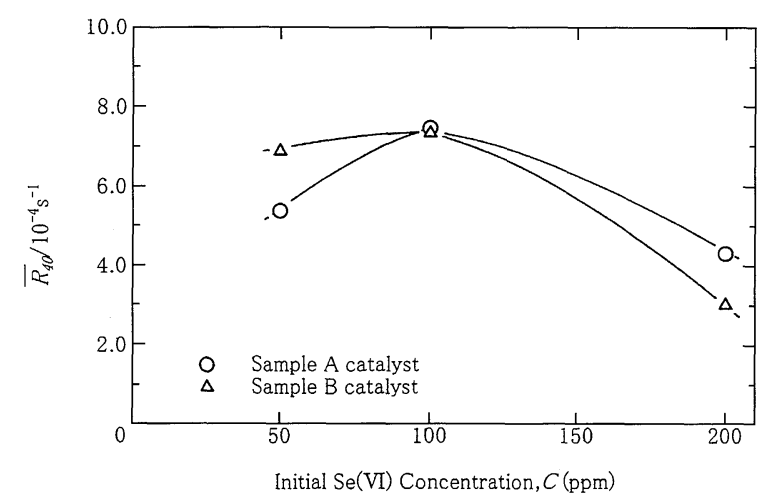

Fig. 10 Effect of initial $\mathrm{Se}(\mathrm{VI})$ concentration on $\bar{R}_{40}$ for the photocatalytic reduction of $\mathrm{Se}(\mathrm{VI})$. $[\mathrm{HCOOH}]: 2.5 \times 10^{-2} \mathrm{kmol} / \mathrm{m}^{3}$, initial $\mathrm{pH}: 3.0, \mathrm{TiO}_{2}$ used: $1.1 \mathrm{~kg} / \mathrm{m}^{3}, \mathrm{~N}_{2}$ gas bubbling, UV irradiation: $48 \mathrm{~W} / \mathrm{m}^{2}$.

solution, whose initial $\mathrm{Se}(\mathrm{VI})$ concentration was $200 \mathrm{ppm}$, proceeded slowly up to $1.8 \mathrm{ks}$ with both catalysts, and accelerated later on.

To compare photocatalytic reductions with sample $A$ to these with sample $B$, mean reduction rates were calculated from the inverse of the time required to reach a $\mathrm{Se}(\mathrm{VI})$ concentration of $40 \mathrm{ppm}, \bar{R}_{40}$, and plotted against initial Se(VI) concentration as shown in Fig. 10. As is clear from this figure, the rate of $\mathrm{Se}(\mathrm{VI})$ reduction was maximal at an initial $\mathrm{Se}$ (VI) concentration of $100 \mathrm{ppm}$ when sample A was used. A similar tendency was observed with sample B, at below $100 \mathrm{ppm} \mathrm{Se}(\mathrm{VI})$, but the reduction was greatly suppressed at an initial Se(VI) concentration of $200 \mathrm{ppm}$. With both sample catalysts, the reduction rates decreased markedly when initial Se(VI) concentrations were high. This may be caused by the slow mass transfer of the product of reduction onto the $\mathrm{TiO}_{2}$ catalyst, and thus the progress of the inverse reaction, re-oxidation of the product, was significant. On the other hand, the decrease of reduction rate observed with the initial $\mathrm{Se}(\mathrm{VI})$ concentration of $50 \mathrm{ppm}$ for sample $\mathrm{A}$ is considered to be caused by the decrease of adsorption amount.

\section{Summary}

Suspensions of the fine particles of two anatase-type $\mathrm{TiO}_{2}$ catalysts with different specific surface areas and particle sizes were used to study the photocatalytic reduction of $\mathrm{Se}(\mathrm{VI})$ in aqueous $\mathrm{Se}(\mathrm{VI})$ solutions. The effects of various factors on reduction rates were elucidated. The main results obtained are as follows:

(1) $\mathrm{Se}^{\circ}$ and $\mathrm{H}_{2} \mathrm{Se}$ were detected during the photocatalytic reduction of $\mathrm{Se}(\mathrm{VI})$, whereas $\mathrm{Se}(\mathrm{IV})$ was not.

(2) The rate of reduction of $\mathrm{Se}$ (VI) was controlled by the amount adsorbed onto each type of $\mathrm{TiO}_{2}$.

(3) Less Se(VI) was adsorbed on sample B with smaller dispersed particle size in comparison with sample A. Nevertheless, the rate of reduction was slightly larger with sample $\mathrm{B}$ than that with $\mathrm{A}$. The energy conversion ratio of the irradiation of UV light, which is calculated from the reduction rate from $\mathrm{Se}^{\circ}$ to $\mathrm{H}_{2} \mathrm{Se}$, is greatly affected by particle size, thus the value is larger for sample $B$ than $A$.

(4) The time required for the reduction of $\mathrm{Se}(\mathrm{VI})$ to $\mathrm{Se}^{\circ}$ and of $\mathrm{Se}^{\circ}$ to $\mathrm{H}_{2} \mathrm{Se}$ with sample $\mathrm{B}$ are proportional to the electrons required for these reactions.

(5) The values of relative energy conversion ratio for sample $A$, estimated from the time required for the reduction of $\mathrm{Se}^{\circ}$ to $\mathrm{H}_{2} \mathrm{Se}$ with samples $\mathrm{A}$ and $\mathrm{B}$, and the amount of $\mathrm{Se}$ (VI) adsorbed, were used to calculate the theoretical time required for the formation of $\mathrm{Se}^{\circ}$ from $\mathrm{Se}(\mathrm{VI})$, which is consistent with the experimental value.

(6) The effects of solution $\mathrm{pH}$, amount of catalyst, formic acid concentration and initial Se(VI) concentration upon the reduction rate of $\mathrm{Se}(\mathrm{VI})$ were examined. It was found that the solution $\mathrm{pH}$ as well as dispersibility of the catalyst powder are important factors affecting reduction in the catalytic reaction of suspension type used in the present study.

\section{REFERENCES}

1) Y. Isshihashi, H. Yamashita and M. Anpo: Kinouzairyo, 16 (1996), 1222.

2) H. Kubokawa, K. Honda and Y. Saito: Hikarishokubai, Asakurashoten, Tokyo, (1988), pp. 53-55.

3) A. Fujishima and K. Honda: Bull. Chem. Soc. Japan, 44 (1971), 11481150 .

4) T. Inoue, A. Fujishima, S. Konishi and K. Honda: Nature, 277 (1979), 637-638.

5) A. L. Pruden and D. F. Ollis: J. Catal., 81 (1983), 404-417.

6) H. Takeuti and S. Nishikata: Kankyokanri, 32 (1996), 915-928.

7) A. Fujishima, K. Hashimoto and Y. Kubota: J. Surface Sci. Soc. Japan, 16 (1995), 188-193.

8) K. Tanaka: Kankyokanri, 32 (1996), 923-928.

9) K. Tanaka: Ceramics Japan, 31 (1996), 825-828.

10) E. Kikuchi: Shigen-to-Kankyo, 6(2) (1997), 173-177.

11) S. Sanuki, T. Kojoma, K. Arai, S. Nagaoka and H. Majima: Metall. Trans. B: 30B (1999), 15-20.

12) M. J. N. Pourbaix, J. Van Muylden and N. de Zhoubov: Atlas d'Equilibres Electrochimiques a $25^{\circ} \mathrm{C}$, Gautier Villard, Paris, (1963), 554-559.

13) I. Iwasaki, A. Kishioka and Y. Yoshida: Bunsekikagaku, 10 (1961), $479-482$. 